\title{
Current Research in Sports Sciences
}

An International Perspective 


\title{
Current Research in Sports Sciences An International Perspective
}

Edited by

\author{
Victor A. Rogozkin \\ Research Institute of Physical Culture \\ St. Petersburg, Russia \\ and \\ Ron Maughan \\ University of Aberdeen \\ Aberdeen, Scotland
}

Springer Science+Business Media, LLC 


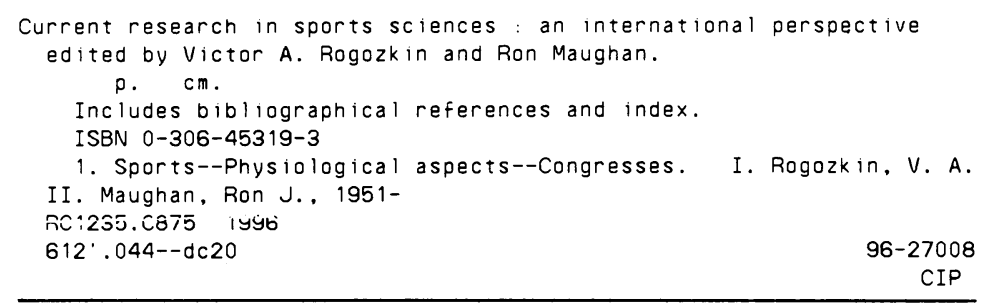

Proceedings of an International Conference on Current Research into Sport Sciences, held in association with the Goodwill Games, July 27 - 30, 1994, in St. Petersburg, Russia

\author{
ISBN 978-1-4419-3255-6 ISBN 978-1-4757-2510-0 (eBook) \\ DOI 10.1007/978-1-4757-2510-0 \\ (C) 1996 Springer Science+Business Media New York \\ Originally published by Plenum Press, New York in 1996 \\ Softcover reprint of the hardcover 1st edition 1996 \\ A Division of Plenum Publishing Corporation \\ 233 Spring Street, New York, N. Y. 10013
}

\title{
All rights reserved
}

10987654321

No part of this book may be reproduced, stored in a retrieval system, or transmitted in any form or by any means, electronic, mechanical, photocopying, microfilming, recording, or otherwise, without written permission from the Publisher 


\section{PREFACE}

There are two main reasons for pursuing research in the Sports Sciences. Firstly, by studying responses to exercise, we learn about the normal function of the tissues and organs whose function allows exercise to be performed. The genetic endowment of elite athletes is a major factor in their success, and they represent one end of the continuum of human performance capability: the study of elite athletes also demonstrates the limits of human adaptation because nowhere else is the body subjected to such levels of intensive exercise on a regular basis. The second reason for studying Sports Science is the intrinsic interest and value of the subject itself. Elite performers set levels to which others can aspire, but even among spectators, sport is an important part of life and society.

Apart from the study of top sport and elite performers, there is also another reason for medical and scientific interest in sport. There is no longer any doubt that lack of physical activity is a major risk factor for many of the diseases that affect people in all countries: such diseases include coronary heart disease, obesity, hypertension, and diabetes. An increased level of recreational physical activity is now an accepted part of the prescription for treatment and prevention of many illnesses, including those with psychological as well as physical causes. An understanding of the normal response to exercise, as well as of the role of exercise in disease prevention, is therefore vital.

Although there is little doubt as to the physical and psychological benefits that can follow from a regular exercise programme, there are also possible negative consequences. The risk of injury associated with the repetitive strain on muscles, joints, and other tissues is obvious. While this may be an acceptable risk in the mature individual, there may be special problems for youngsters who train intensively. The identification of sporting talent in youngsters and its development so that potential is realised without compromising physical and psychological development poses special problems.

To address some of these issues, a major international Conference was held in association with The Goodwill Games in St. Petersburg, Russia, in July 1994. This Conference was unique in many respects, as it was the first in the field of exercise science and sports medicine to bring together scientists and clinicians from Western and Eastern Europe, North America, the Republics of the Former Soviet Union, and from the rest of the world. More than 400 participants from 42 countries contributed to the meeting. For many years, the fiercely competitive nature of international sport had stimulated interest and speculation about the advances made in Sports Science in other countries and had provided an impetus to research in this area. This conference offered an opportunity for a free exchange of information and ideas, and these proceedings are a permanent record of the presentations made. 
The programme of the conference focused on three broad areas: (1) the identification and development of sporting talent, (2) reaching and maintaining peak performance, and $(3)$ the relationships between physical activity and wellness. This volume contains selected papers in all of these areas, providing a broad overview of key issues in Sports Science, including much information that has not been available until now.

Thanks are due to many people for the contributions that made a success of the conference and who have allowed the production of these proceedings. Much of the editorial work was accomplished with the help of Susan Shirreffs in Aberdeen. Special thanks are due to Mars Incorporated for their major commitment to support high quality research and education in exercise science and sports nutrition, for their sponsorship of the meeting. and for the organisational skills that helped to ensure its smooth running.

V.A. Rogozkin and R.J. Maughan 


\section{CONTENTS}

1. Identification and Development of Talent in Sport $\ldots \ldots \ldots \ldots \ldots \ldots \ldots$ V. K. Balsevich

2. Expert Coaches' Strategies for the Development of Expert Athletes $\ldots \ldots \ldots \ldots$ John H. Salmela

3. Selection of Children for Sports $\ldots \ldots \ldots \ldots \ldots \ldots \ldots \ldots \ldots \ldots \ldots \ldots \ldots \ldots \ldots$ W. Starosta

4. Control of Motor Function and Its Role in Selection and Orientation of Young

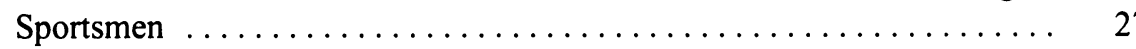
O. M. Shelkov and G. A. Hrisanfov

5. Neurological and Pathopsychological Criteria for Sport Selection

T. P. Koroleva

6. Correlation of Physical Working-Capacity with Morphofunctional

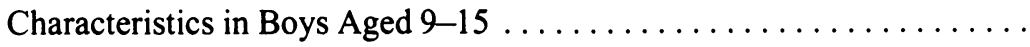

A. G. Falaleev, V. A. Kobzev, and S. V. Cherenina

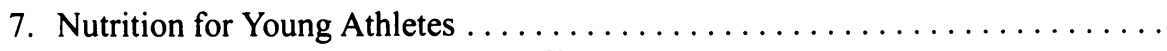

R. J. Maughan and S. M. Shirreffs

8. Fat and Fat Distribution in Elite Rhythmic Gymnasts Marie-José Borst, Willy Pieter, and Nadeshda Yastrjembskaya

9. Body Composition and Nutritional Intake in Belgian Volleyball Players ...... Marina Goris, Christophe Delecluse, Rudi Diels, Ruth Loos, and Sigi Celis

10. A Computer System for Analysis and Correction of Antioxidant Intake

A. Ivanov

11. Mental Training for Sport and Life

L.-E. Uneståhl

12. Professional Sport as Sub-Culture

N. I. Ponomarev 
13. Psycho-Pedagogical Analysis of Individual Style of Operational Problem

Solving

A. V. Rodionov

14. Prediction of the Efficiency of Skilled Athletes

V. I. Balandin

15. Mental Relaxation - Neuro-Dynamic Markers and Psychophysiological

Mechanisms ............................... 91

P. Bundzen, P. Leisner, A. Malinin, and L.-E. Uneståhl

16. Long-Acting Regulators of Mental State in Elite Sport: Control and

Optimization of Their Influence

G. B. Gorskaya

17. Effects of Mental Training on Sense of Rhythm

M. V. Yermolaeva and M. M. Chirkova

18. Experience of the Application of Meditation to Shaping

T. V. Alfyorova-Popova and O. Votyakova

19. Anatomical Data for Biomechanical Calculations

I. M. Kozlov, A. V. Samsonova, and A. B. Sinukhin

20. Mathematical Modelling of Sports Human Movements

L. A. Khasin and M. L. Ioffe

21. The Control of Movement

S. P. Evseev

22. The Application of Computer Technologies to the Management of Sport

Specific Training in Rhythmic Sports .

V. Kleshnev

23. Computer Software for Canoeing Simulation: General Opportunities

I. Sharobaiko, P. Temnov, A. Korotkin, and T. Gladilova

24. Nutritional Preparation for Sports Performance: The Elite Performer

R. J. Maughan and Louise Burke

25. Ergogenic Effects of the Creatine Supplementation during the Training of

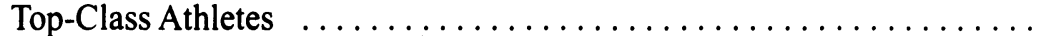

Nikolai I. Volkov, Egon R. Andris, Yurij M. Saveljev, and

Vladimir I. Olejnikov

26. Effect of Products of Enhanced Biological Value on the Performance of Athletes

A. Pshendin, N. Shishina, and V. Zagrantsev

27. The Metabolic Basis of Rowing: Variability of Energy Supply and Possibilities of Interpretation .

U. Hartmann and A. Mader 
28. Relationships between Fatigue and Rehabilitation $\ldots \ldots \ldots \ldots \ldots \ldots \ldots$ V. Volkov

29. Energetic, Biomechanical, and Electromyographic Characteristics of Elite

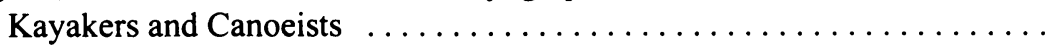

V. Timofeev, K. Gorodetsky, A. Sokolov, and S. Shklyaruk

30. Myocardial Dystrophy in Athletes: A New Approach to an Old Problem ....... 199 V. Zemtsovsky

31. New Methods for the Measurement of Specific Working Capacity of Top-Level Athletes (Dynamics of Training Development) . . . . . . . . . . 205 F. A. Iordanskaya

32. Finger Dermatoglyphs as Markers of the Functional Features T. Abramova, T. Nikitina, E. Shafranova, N. Kotchetkova, and G. Secamova

33. Measurement of Anaerobic Performance Characteristics of Athletes Heikki K. Rusko

34. Physical Activity, Physical Fitness, and Health 225 Steven N. Blair

35. The Value of Physical Culture in a Healthy Life-Style

L. I. Lubysheva

36. Physical Activity Levels of School-Aged Children in St. Petersburg

A. G. Komkov, G. L. Antipov, and E. G. Gurinovich

37. The Effects of Fitness and Quality of Health on Rating of Perceived Exertion .. 255

O. M. Evdokimova

38. Influence of Ecological Conditions on the Physical Activity and Physical Status of Schoolchildren

K. F. Kozlova

39. A Screening Method for Fitness Assessment

U. N. Utenko, D. N. Gavrilov, and D. A. Ivanova

40. Factors of Unfitness (Fitless Factors)

L. A. Kalinkin, E. V. Kuzmichova, V. D. Kriazev, and A. L. Kalinkin

41. Physical Fitness in Polish Children and Adolescents

R. Przeweda

42. Individual Approach in Exercise for Health

V. D. Sonkin, V. V. Zaytseva, O. V. Tiunova, M. V. Burchik, and D. A. Phylchenkov

43. Comparison of Testing Methods for the Assessment of Aerobic Endurance .....

D. N. Gavrilov and T. V. Zabalueva 
44. Effect of Exercise Training and Acute Exercise on Essential Hypertensives . . . 295

R. D. Dibner, M. M. Shubin, N. Taylor-Tolbert, D. R. Dengel. S. D. McCole, M. D. Brown, and J. M. Hagberg

45. Self-Resistance Gymnastics and Physical Rehabilitation of Wheelchair-Disabled in Russia .................................. 303 V. S. Dmitriev, A. I. Osadchih, and E. V. Ozolina

46. Nutrition, Moderate Exercise, and Health Adrianne E. Hardman

47. Metabolic and Ventilatory Effects of Caffeine during Light Intensity Exercise in Trained and Sedentary Low Habitual Caffeine Users $\ldots \ldots \ldots . . \ldots 321$ H.-J. Engels, J.C. Wirth, and E.M. Haymes

48. Exercise Training and High Carbohydrate Diet: Effects of Vitamins $\mathrm{C}$ and B6 . O. V. Karpus and V. A. Rogozkin

49. Radioisotopic Investigation of Gastric Emptying and Small Intestine Function at Different Exercise Levels

A. P. Kuznetsov, V. I. Kozhevnikov, and A. V. Rechkalov 